\title{
Finite Element Analysis of Draw Beads in Deep Drawing Processes
}

\author{
Alaa Dahham \\ University of Mosul
}

\author{
Dr. Azal Refa $`$ \\ University of Technology
}

\author{
Dr. Muhsen Jaber \\ Al-Nahrin University
}

\begin{abstract}
The design optimization of deep drawing process in manufacturing is proposed to control the final shape of the work piece after elastic spring back. The manufacturing process design problem is formulated to minimize the difference between the shape of the desired work piece geometry and the final analysis. This paper aims to predict the wrinkling and thinning (necking) failure and to study the effect of using draw bead on the thickness distribution along the cup. In this paper to analysis the deep drawing process with draw beads the FEM code (ANSYS) version 12.1 packages is used, which is able to simulate various metal forming processes such as deep drawing. The best results and the low variation between the maximum thickness and minimum thickness is found at the half circle shapes of Draw Bead and its about $10.4 \%$ thinning and $26.5 \%$ thickening
\end{abstract}

Keywords: Deep Drawing, Draw bead, and ANSYS 12.1.
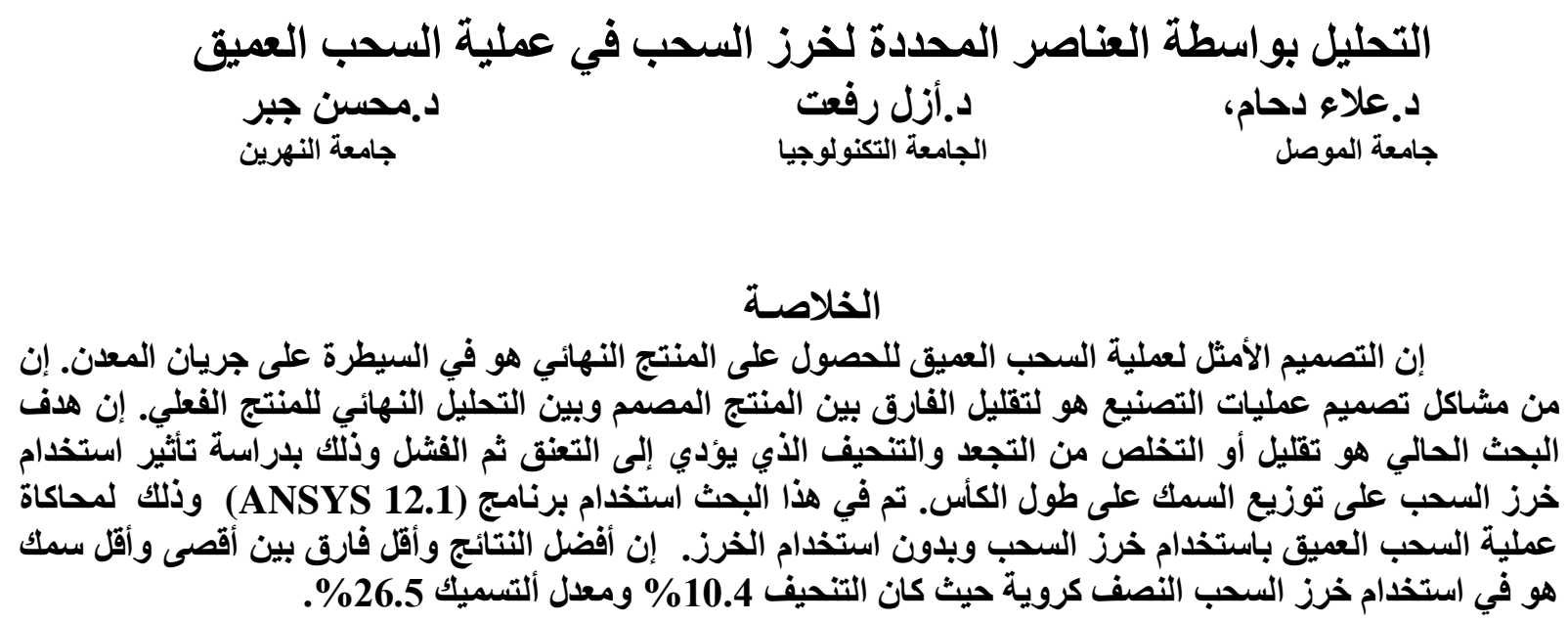


\section{Nomenclature}

\begin{tabular}{|c|c|c|}
\hline $\mathbf{a}$ & Half contact area & $\mathbf{m m}$ \\
\hline $\mathbf{p}$ & Pressure contact & $\mathbf{M P a}$ \\
\hline$P_{b h}$ & Holding force & $\mathbf{M P a}$ \\
\hline$\theta$ & Angle of contact & Degree \\
\hline$\mu$ & Coefficient of friction & \\
\hline $\mathbf{E}$ & Modulus of elasticity & $\mathbf{G P a}$ \\
\hline$v_{1}, v_{2}$ & Poisson ratio & \\
\hline $\mathbf{R}$ & Radius of surface & $\mathbf{m m}$ \\
\hline
\end{tabular}

\section{Introduction}

In deep drawing process the blank is clamped between the die and the blank holder. The blank holder is loaded by a blank holder force, which is necessary to prevent wrinkling and to control the material flow into the die cavity. The punch is pushed into the die cavity, simultaneously transferring its specific shape and the die to the blank. When a very high blank holder force is applied, the deep drawing process becomes a stretching process [1].

In sheet metal forming process many factors have to be considered such as drawing force, blank holder force, friction force ....etc. The energy source for this deformation may be a hydraulic press at one end of the scale, mechanical press, or a high - explosive charge at the other [2]. Deep drawing is a process in which a blank or work piece is usually controlled by a pressure plate, forced into and/or through a die by means of a punch to form a hollow component in which the thickness is substantially the same as that of the original material [3]. The draw beads are one of the most important parameter to control the material flow and Thus the part quality in the sheet forming process see figure (1).
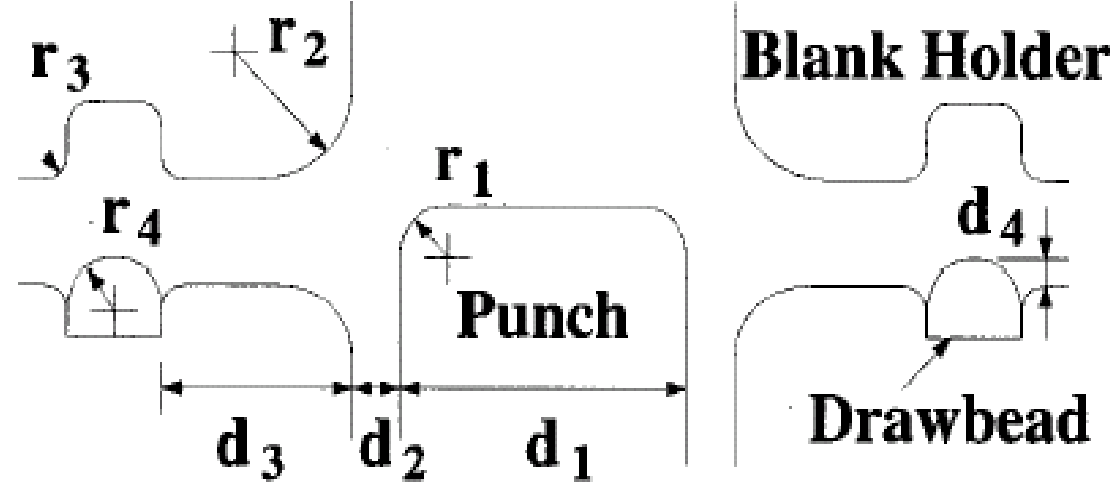

Fig. (1) Deep drawing with draw beads [4].

Very strong restraining force prevents the sheet from drawing in and may cause necking, but insufficient forces may lead to wrinkling[4]. The draw bead geometry modelling will lead to a large number of elements on the small radii of draw beads, in addition, the position and shapes of draw beads require several modifications during the forming tool design, so that the draw beads are often replaced by equivalent restraining forces in sheet forming simulation. 
The work required to pull (or to restrain) a sheet through a draw bead is equal to the work required to overcome the sheet/tool friction and to bend or unbend the sheet [5].

\section{Draw beads design}

Fig. (2), Shows the development of deformation in a circular draw bead with square female. As the metal pass through the draw bead, it undergoes bending deformation at point. The sheet is bent to the radius of the groove shoulder. The bending is complete in a short path length equal to the sheet metal thickness at the bending position (point 1). Sliding between points 1 and 2 generates a friction force. At point 2, the metal is straightened (unbended) and slide at the radius of the groove shoulder.

This sequence of bend, slide and unbend accounts for restraining force from the first groove shoulder. The same sequence occurs in the arcs 3-4 and 5-6. The entire restraining force of the draw bead is due to the work done in the three bending and unbending sequence plus the friction force between the bead and the sheet.

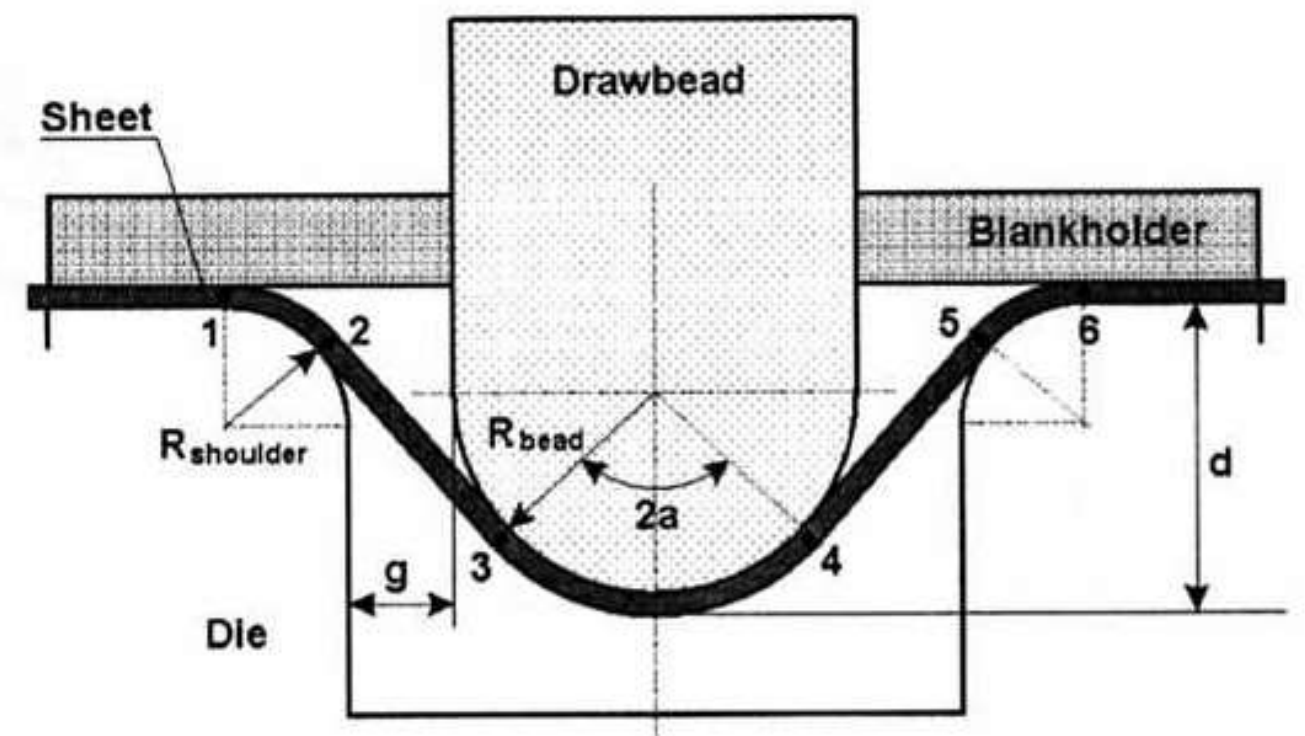

Fig. (2) Draw bead geometry [5].

\section{Action of the draw bead}

The estimation of the draw bead restraining force can be obtained based on experiments, analytical formulas or 2D simulation. This model is based on the principle of virtual work: the work required to pull (or to restrain) a sheet through a draw bead is equal to the work required overcoming the sheet /tool friction and to bend or unbend the sheet.

The virtual plastic work due to bending - unbending gives the restraining force $F$ (per unit of length) including friction can be obtained as follows fig. (2) [4]:

$$
F=\left(\left(F_{1} e^{\mu \vartheta}+\mu P_{b h}+F_{2}+F_{3}\right) e^{2 \mu \vartheta}+\mu P_{b h}+F_{4}+F_{5}\right) e^{\mu \vartheta}+F_{6}
$$


To calculate the distribution pressure on draw bead, the problem of contact between bodies whose geometry is defined by circular arcs. This problem was first solved by Hertz for elastic contact and is generally referred to as hertzian contact.

The actual contact pressure distribution $\mathrm{P}$ has the form [6].

$$
\begin{aligned}
& P=\frac{2 F_{B H}}{\pi a}\left(1-\frac{x^{2}}{a^{2}}\right)^{\frac{1}{2}} \\
& a^{3}=\frac{4 F_{B H} \bar{R}}{\pi \bar{E}}
\end{aligned}
$$

The results may be reasonably used for other contact geometries:

$$
\begin{aligned}
& \frac{1}{\bar{R}}=\frac{1}{R_{1}}-\frac{1}{R_{2}} \\
& \frac{1}{\bar{E}}=\frac{1-v_{1}^{2}}{E_{1}}+\frac{1-v_{2}^{2}}{E_{2}}
\end{aligned}
$$

For the case of a cylinder on a plane, the radius of the plane is taken as infinity,

There by $\mathrm{R}$ becomes the radius of the cylinder only and for concave curvatures the radius is taken as a negative. It is also worthwhile noting that when $\mathrm{E} \rightarrow \infty$, the solids become rigid leading to a signal point contact where $\mathrm{a} \rightarrow 0$.

\section{Numerical Simulation}

The finite element method simulation is usually carried out under the working conditions specified by the users. The users repeat the simulation by changing the conditions until an acceptable to reduce such efforts of the users by determining an appropriate condition of numerical simulation, which used to:

- Predicting the material flow during the particular process (on the draw beads in deep drawing).

- Predicting the punch force, blank holder force and the stresses necessary to execute the forming process.

- Prevent the failure caused by the defect in tooling design.

In this work the commercial FEM code (ANSYS 12.1) are used to simulate the process of draw bead in deep drawing operation. Cup forming was created and the numerical results were compared with the experimental results.

The punch, die and the blank holder represented by (Target 169), which defined by three nodes having two degrees of freedom at each node.

The blank material represented by (Visco 106), which defined by four nodes having up to three degrees of freedom at each node.

The contact interface between die and the deformed material is represented by (Contact 171), which has two degrees of freedom at each node [7].

The loading was conducted in the form of a prescribed displacement. The total travel of punch was $(\mathrm{y}=40 \mathrm{~mm})$.

Isotropic Hardening Plasticity model was used, the plastic response was modeled using the Von Mises Yield Criterion. 


\section{Specific problem}

A typical cylindrical cup drawing process was chosen for detailed analysis in deep drawing process with draw beads. The cup without flange, and completely drawn into the die. In this paper, Half circle (HC)-shape of Draw Beads is used lied on the blank holder.

Figure (3) Show the modelling system is composed of the press, blank holder, blank (sheet metal) the shape of Draw Bead lie on the blank holder and die. This cup without flange, and completely drawn into the die shown in figure (4) and (5).

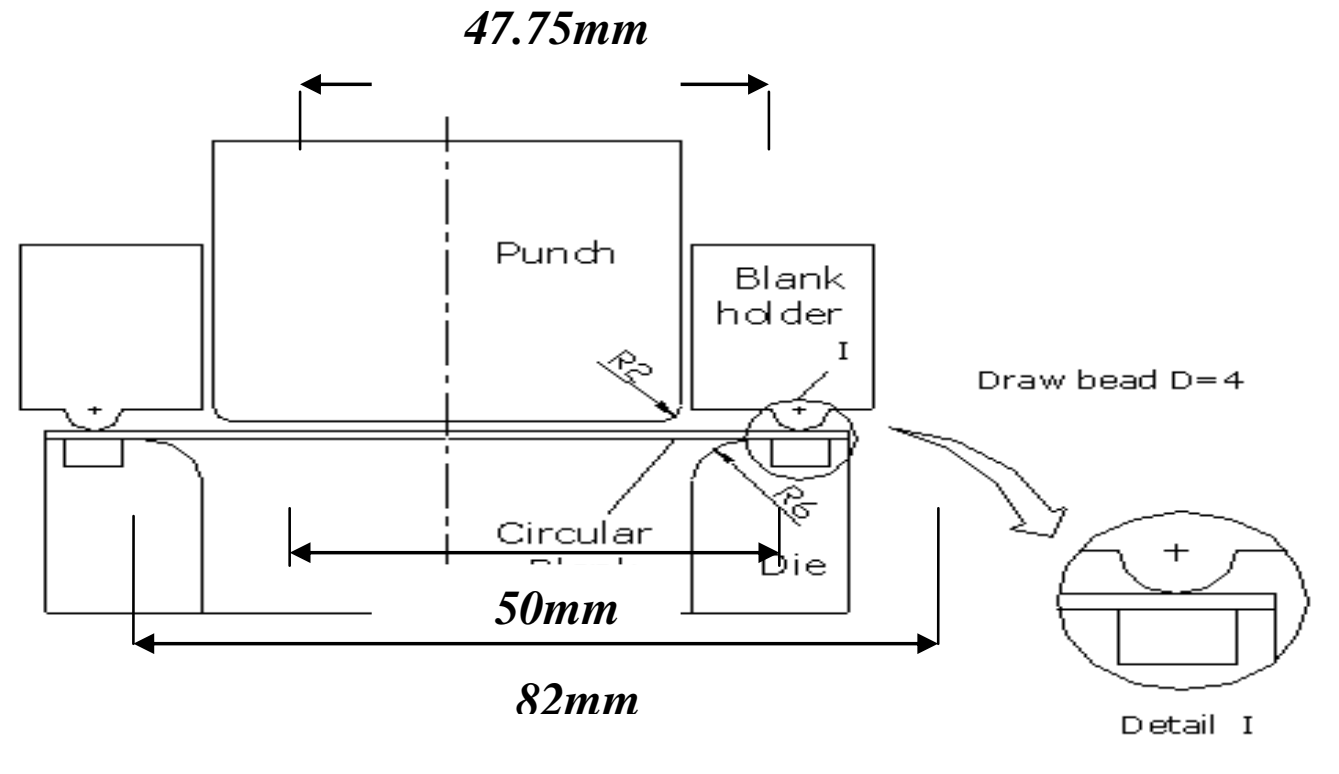

Fig. (3) Draw bead having Half circle-shape

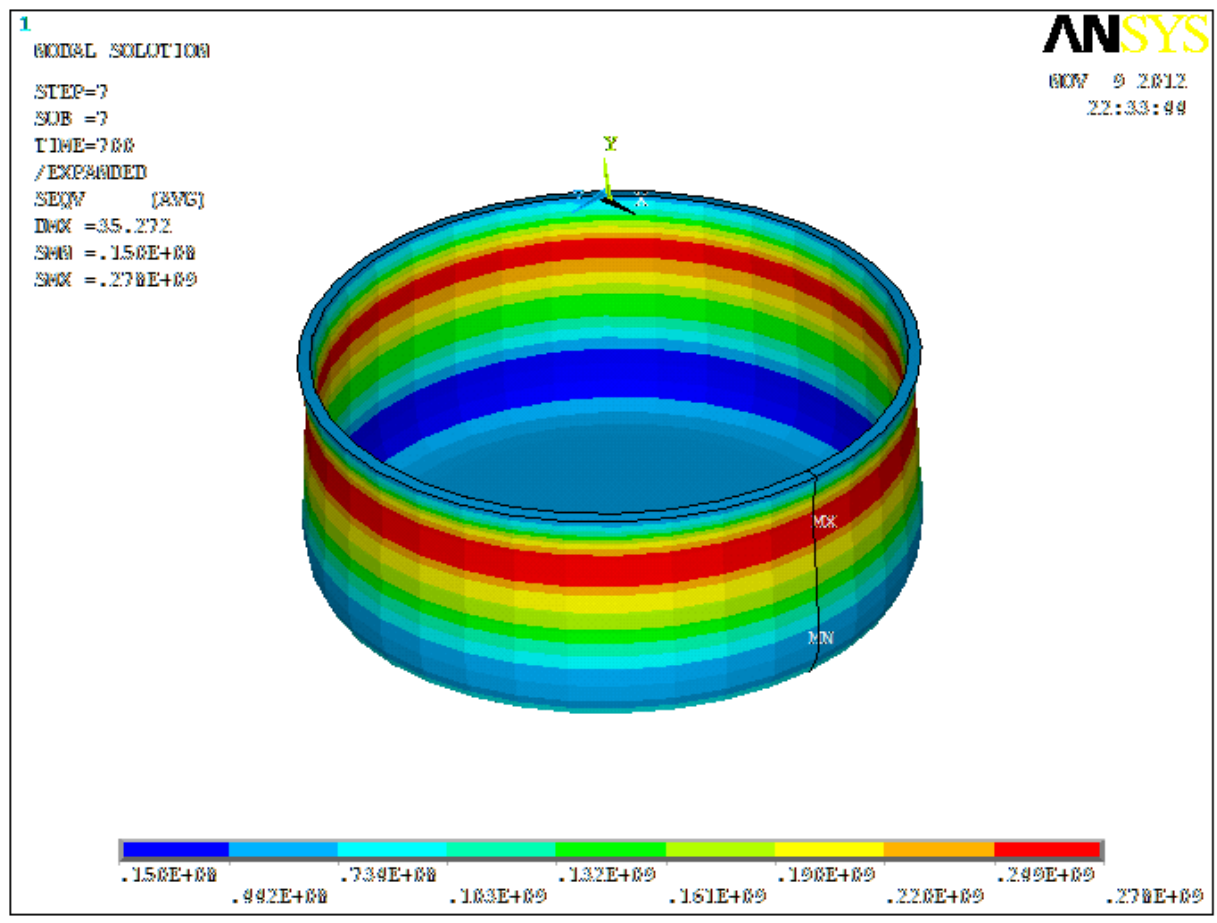

Figure (4) 360 2-D axisymmetric symmetry expansion of the deformed cup 


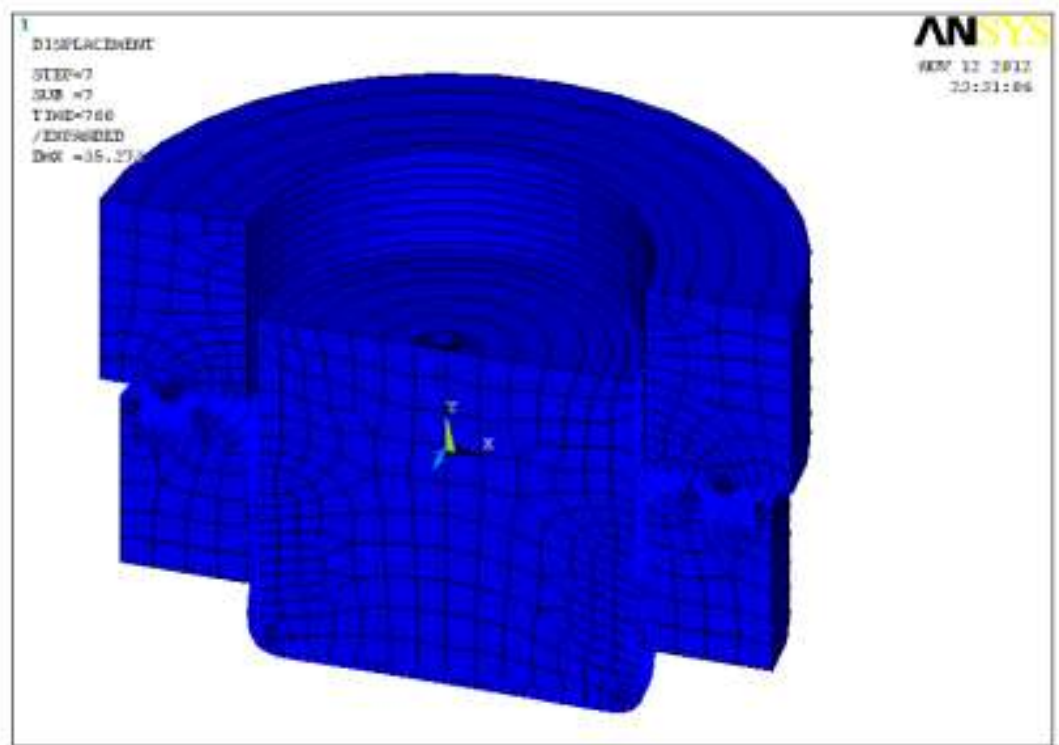

Figure (5) 180 2-D axisymmetric symmetry expansion finite element model

\section{Experimental tooling}

The dimensions of punch and die used in experiments work is:

- The punch $(47.1 \mathrm{~mm})$ diameter with corner radius $d_{p}=2 \mathrm{~mm}$.

- The die $(49.9 \mathrm{~mm})$ inner diameter with the corner radius $d_{d}=6 \mathrm{~mm}$.

- The blank (82 mm) diameter with $1 \mathrm{~mm}$ thickness.

The experiment was carried out using the INSTRON testing machine which has a capacity of machine $100 \mathrm{kN}$ the crosshead speed of the testing machine was kept constant at $10 \mathrm{~mm} / \mathrm{min}$. Figure (6) shows the tools of deep drawing such as die, punch and blank holder force.

Figure (7) show the sample of completely drawn cup

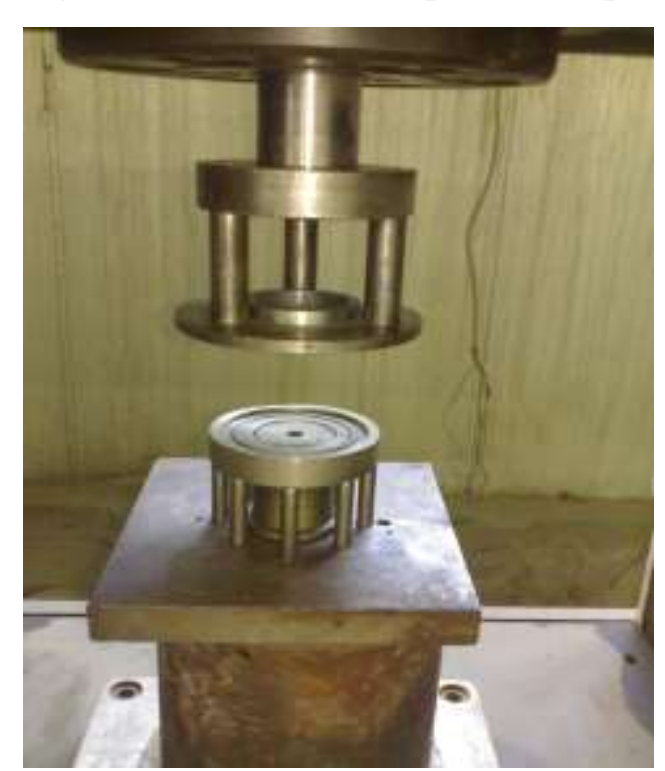

Figure (6) Deep drawing tools

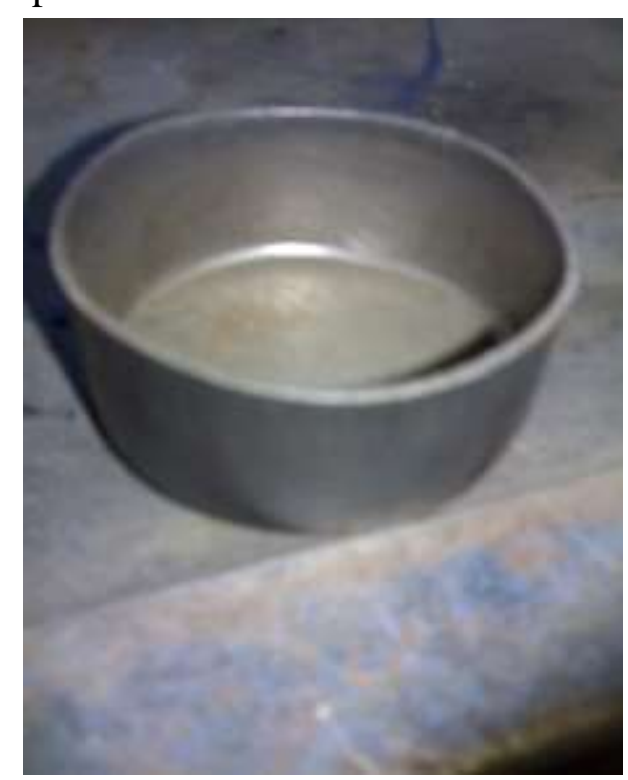

Figure (7) the sample of completely drawn cup 


\section{Results and discussion}

In this paper, to investigate the effect of using draw bead in the deep drawing process and without using draw bead (WB) on strain, stress and thickness distribution along the cup.

The die profile radius configuration used in this step is set to be [p2d6], in which (p2), mean that the punch profile radius (corner radius) is equal to $(2 \mathrm{~mm})$ and (d6), mean that the die profile radius (corner radius) is equal to $(6 \mathrm{~mm})$. The initial blank holding force used in the simulation is $(10 \mathrm{kN})$. The coefficient of friction used in the simulation is $(\mu=0.1)$ and a square female is used for all above cases.

Fig. (8) Shows the forming progress stages of deep drawing process using Draw Beads, notice the bending and unbending of the sheet metal at the initial stage up to the final product.

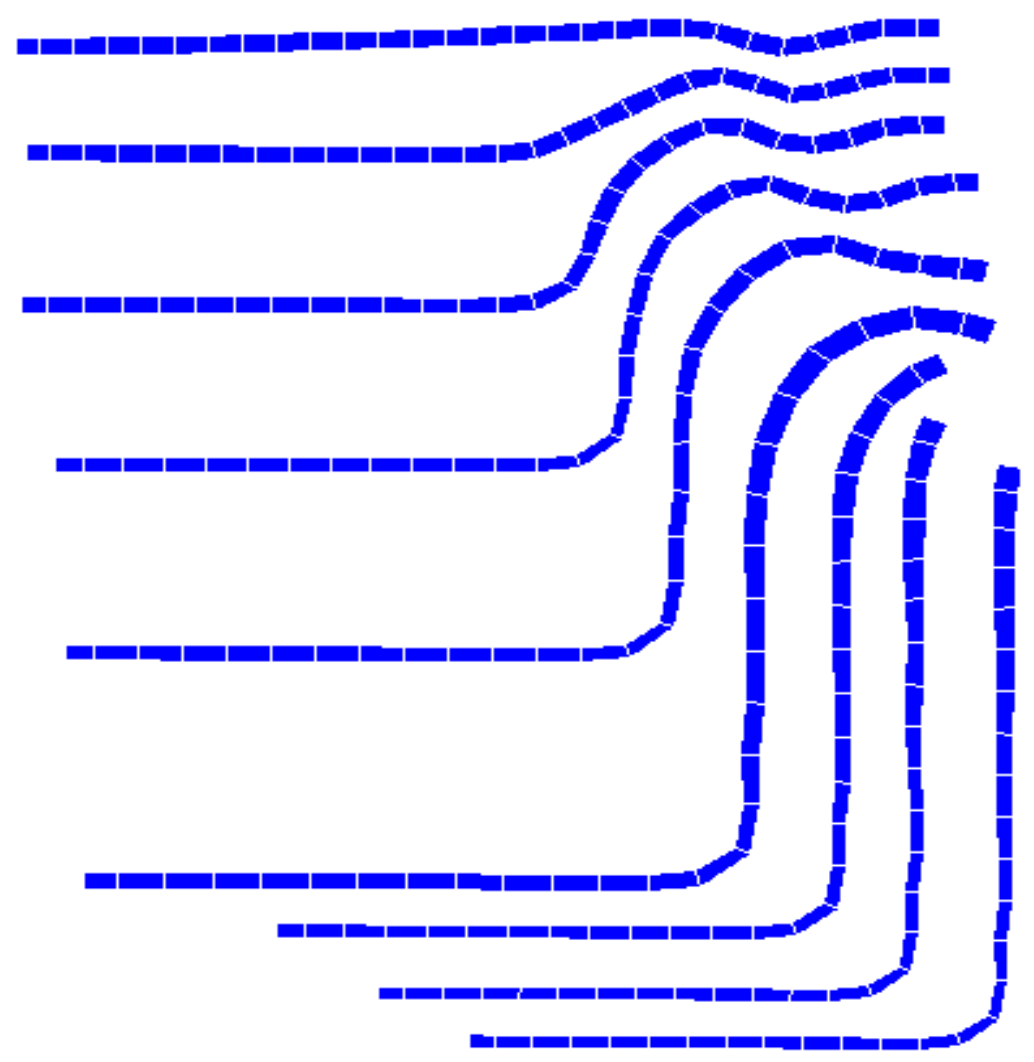

\section{FIGURE (8) the stages of forming sheet metal in deep drawing with draw bead.}

Figure (9) represents the relationship between the strain and the distance from cup centre, where the radial strain Ex is constant under the punch base and then increase on the cup wall getting positive value where metal is subjected to strain and tension in the radial direction. The strain Ey along the work piece, where it's constant under the punch base and then decreases with negative values at punch edge and after that the strain increases on the cup wall and getting positive value. The circumference strain Ez, it's constant under the punch 
base and then getting negative values on the cup wall where the metal is subjected to compression stress along the circumference.
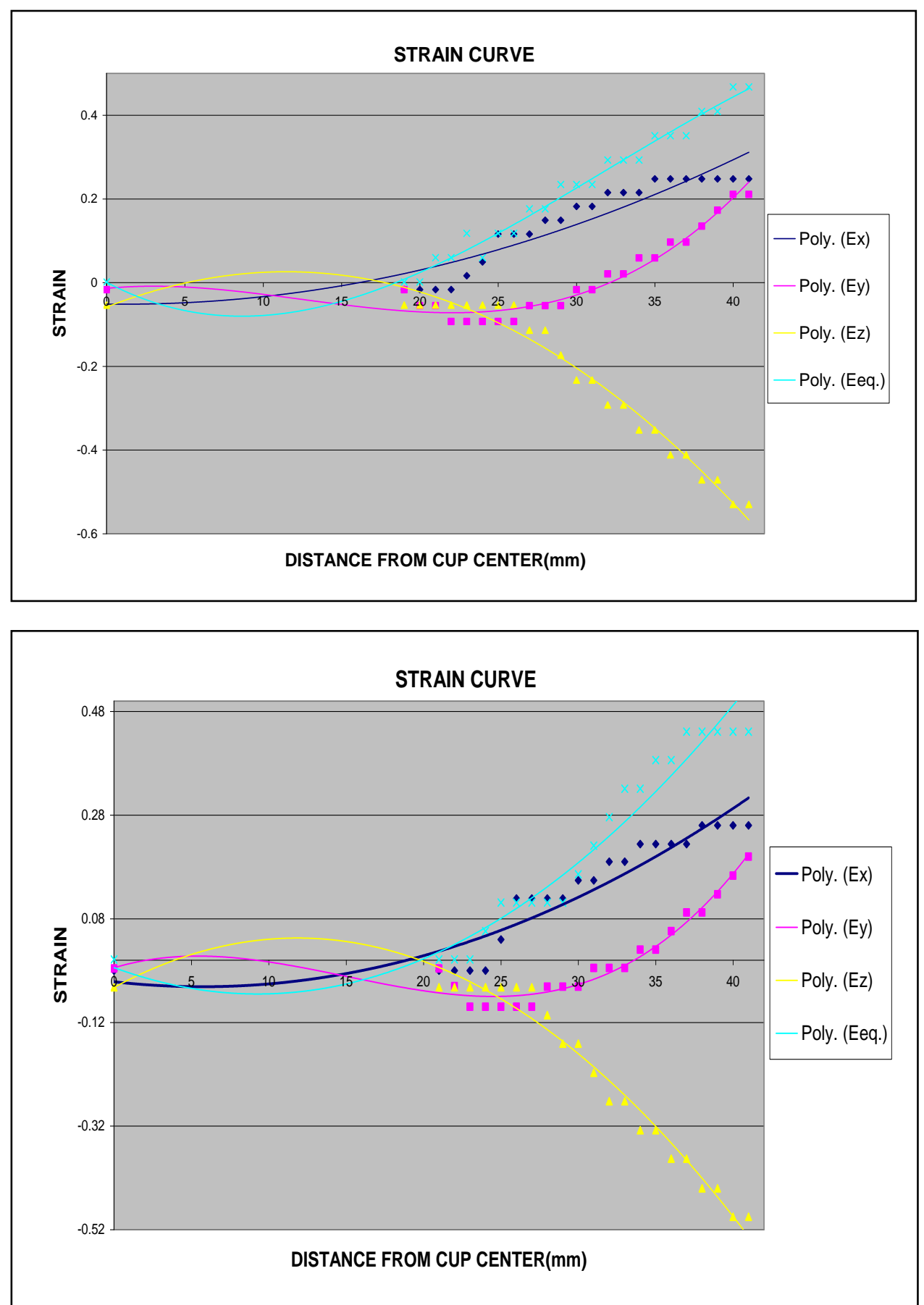

Fig. (9) The effect of using draw bead or without using draw bead on strain 
Figure (10) represents the relationship between the stress and distance from cup centre, the stresses that occurred on the internal edge of the product have been chosen because of the variation of stress values across the metal thickness.

The radial stress Sx increases with the force that acting on the blank where having positive values under the punch base and that is due to tension effect and then starting decreases on the cup wall where the tension force has no effect at the end of the cup edge. The thickness stress Sy is always taking low values with uniform behaviour. The circumference stress $\mathrm{Sz}$ is constant under the punch base and then obtaining negative values on the cup wall where it is a compression stress
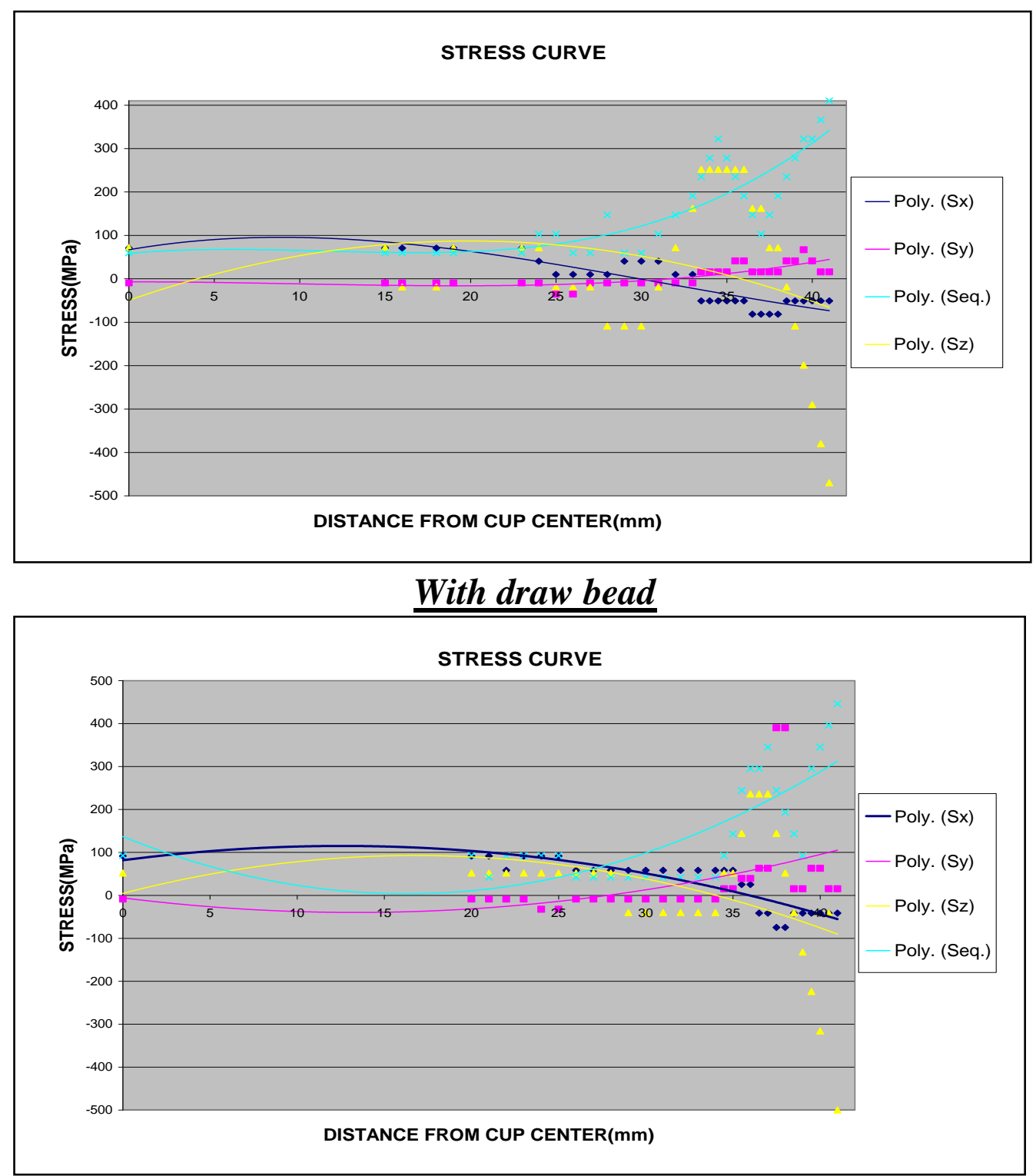

without draw bead

Fig. (10) The effect of using draw bead or without using draw bead on stress 
Fig. (11) Represents the relationship between draw force (punch load) and displacement in theoretical and experimental for the HC-shape and without using draw bead. Observing that there is no difference approximately between the theoretical and experimental.
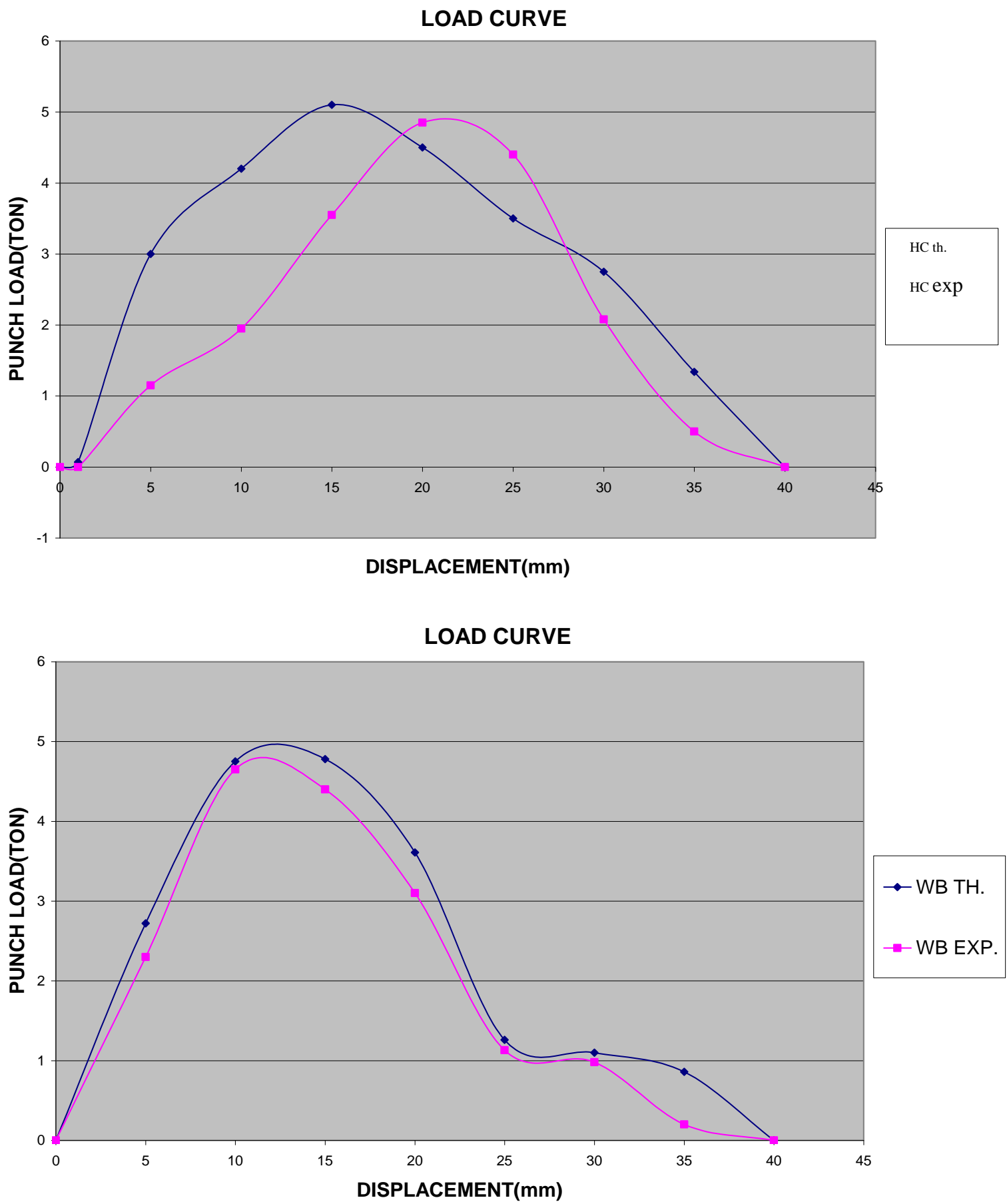

Figure (11) the difference between theoretical and experimental on punch force.

Thickness Distribution 
Figure (12) represents the relationship between the thickness strain and the distance from cup centre, observing that the thickness is constant under the punch base and then increases on the cup wall.

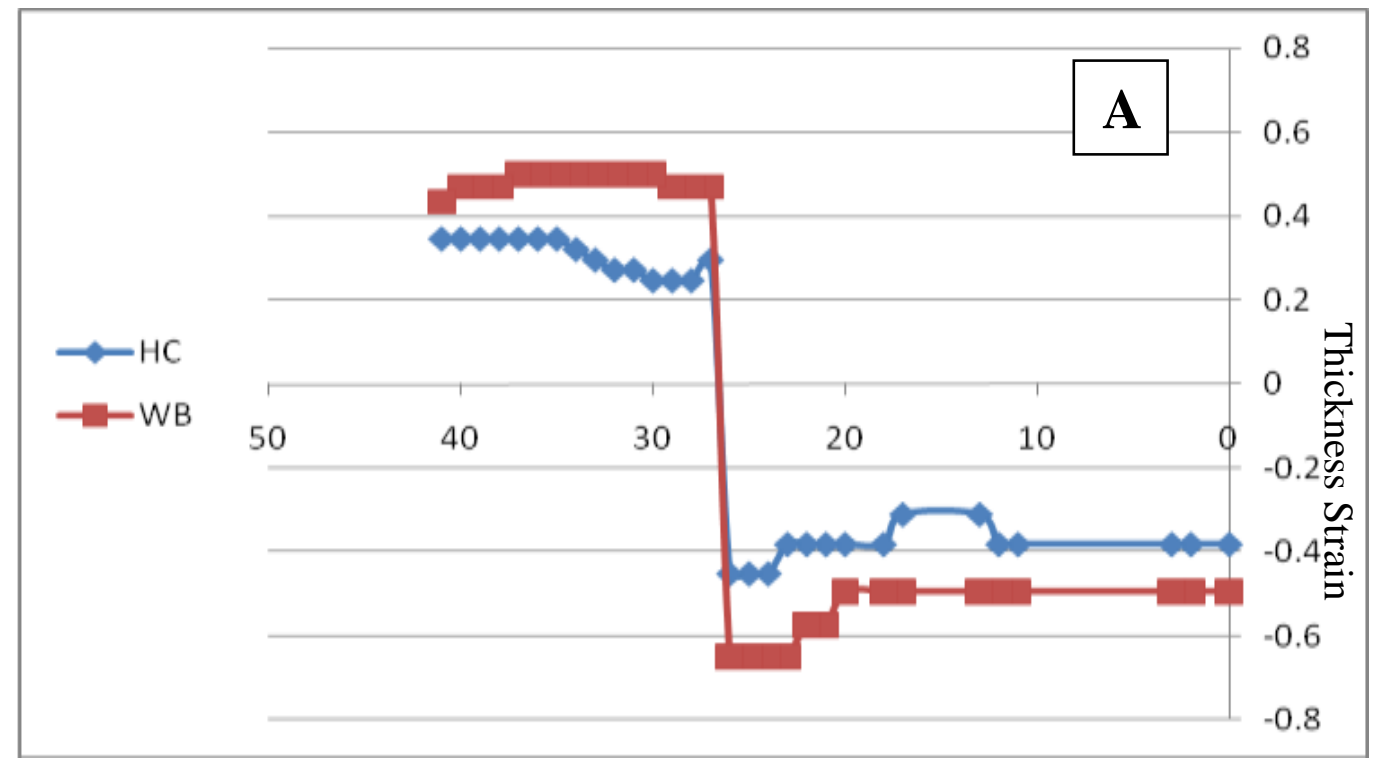

DISTANCE FRON CUP CENTER (mm)

Fig. (12.A) The effect of using draw bead or without using draw bead on thickness distribution

Thickness Distribution

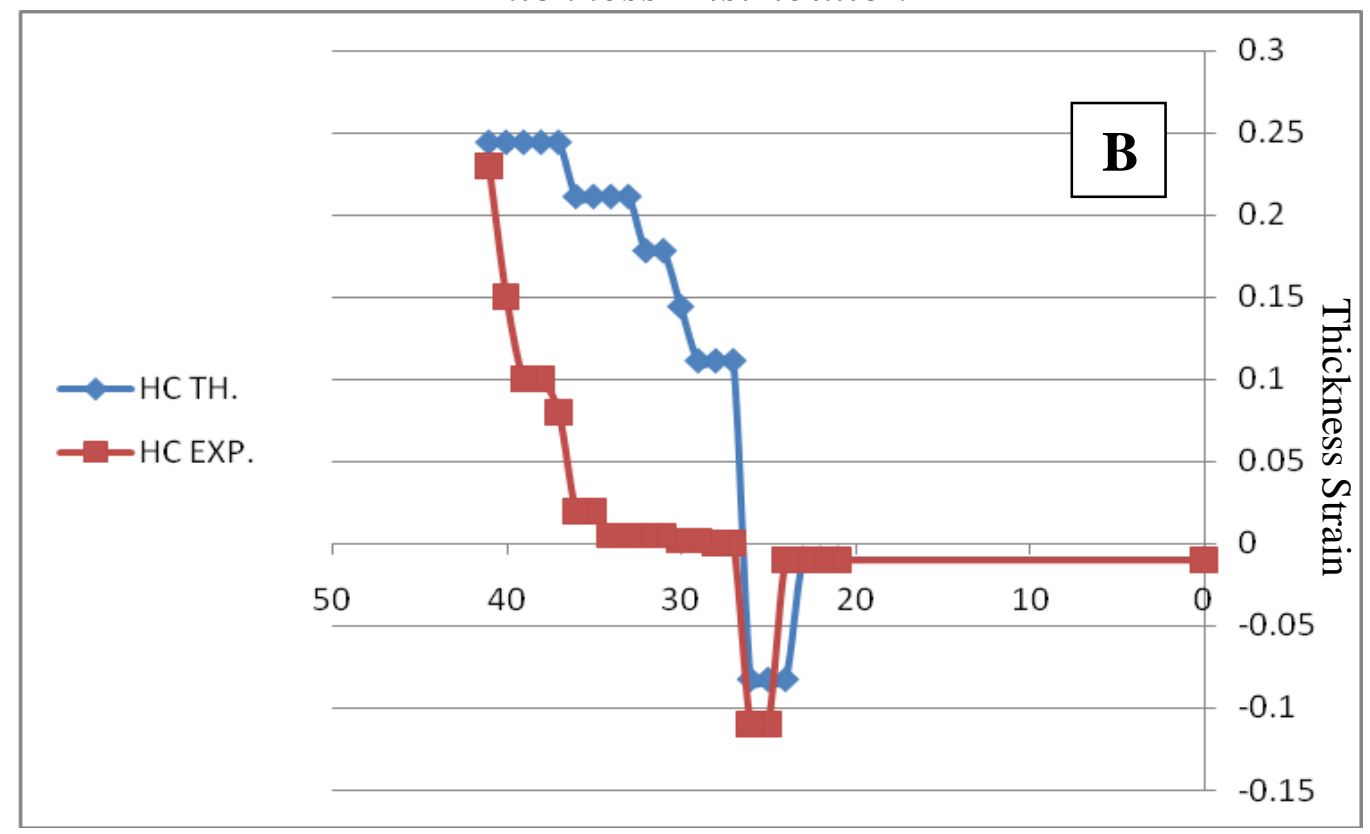

DISTANCE FROM CUP CENTER ( $\mathrm{mm})$

Fig. (12. B) The effect of using draw bead or without using draw bead on thickness distribution 


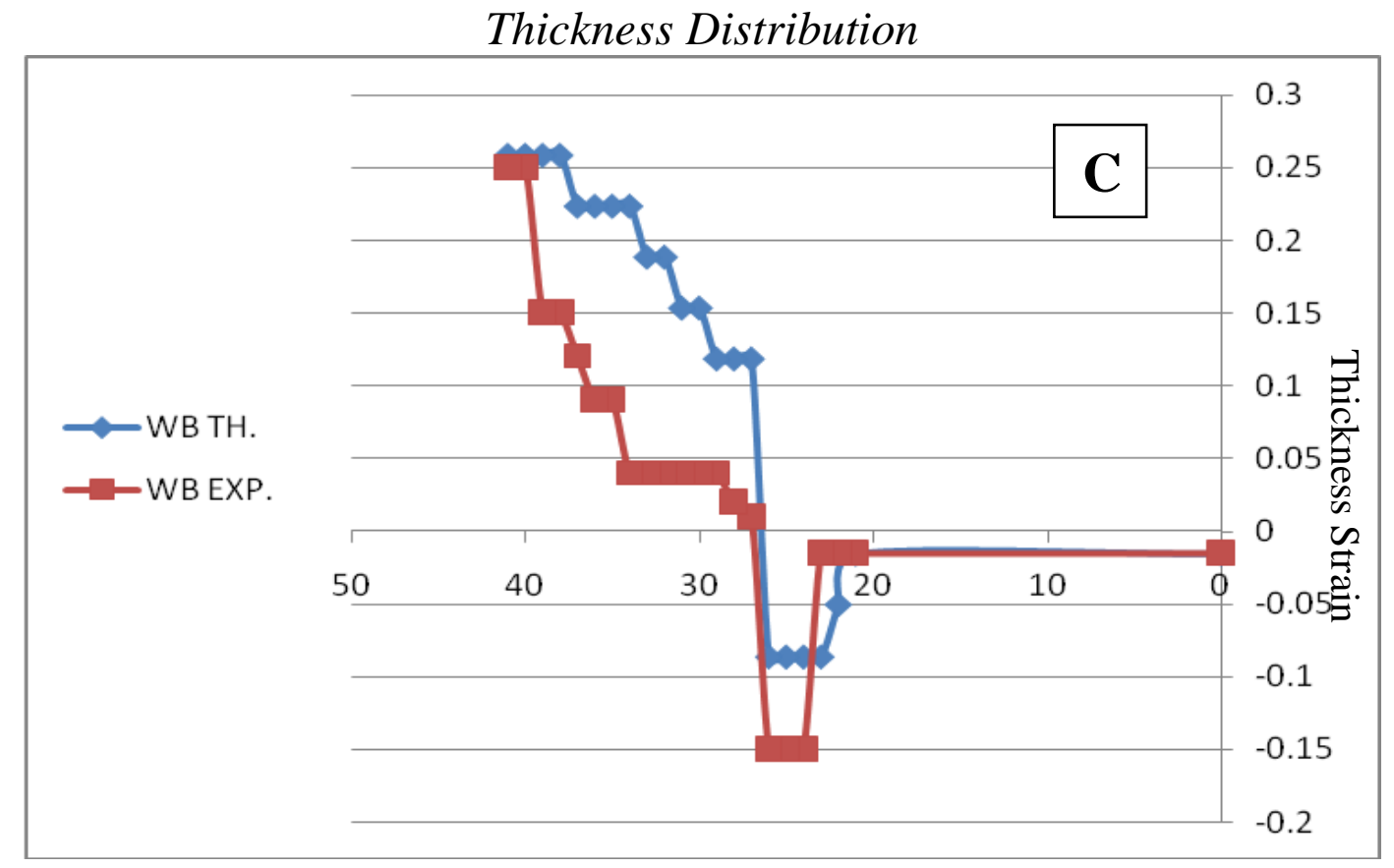

DISTANCE FROM CUP CENTER ( $\mathrm{mm})$

\section{Fig. (12. C) The effect of using draw bead or without using draw bead on thickness distribution}

\section{7) Conclusions:}

1. Drawing force increases when using of the draw bead and that's due to the large resistance which increases the friction force and therefore a larger force is required to overcome that resistance.

2. Larger stresses concentrated at the radii of the punch and die edges.

3. The constriction usually occurs at the radius of the punch edge.

4. when comparing between deep drawing with draw bead and without using draw bead the energy required to complete drawn when using draw bead is more than without draw bead but the thickness strain distribution (predominate) along the blank is more uniform for using draw bead than without using draw bead and is about $10.4 \%$ in thinning and $26.5 \%$ in thickening.

\section{References}

1. Langerak .N.A.J and S.P.Kragtijk, the use of finite element models in the development of alight weight steel and aluminum car body, proceedings of the $2^{\text {nd }}$ as a form conference of material forming 1999.

2. William .F.Waller, A.M.I.T.P.P., Ass.I.Ref.Eng, design engineering series, metals, vol. $1,1970$.

3. Kurt Lange, Hand book of metal forming, university of Stuttgart, 1985. 
4. C.W.Hsu, A.G.Uisoy and M.Y.Demeri, an approach for modeling sheet metal forming for process controller design, Journal of manufacturing science and engineering, vol.122-November 2000.

5. H.Naceur, Y.Q.Guo, J.L.Batoz, C.Knopf-Lenoir, optimization of draw bead restraining forces and draw bead design in sheet metal forming process, International journal of mechanical sciences 43 (2001).

6. Frank W.Wilson, Philip D.H and Charles B.G, Die design (Hand Book), engineers second edition-section 11.

7. ANSYS 12.1 on-line Help. 